\title{
Inside English/language arts standards: What's in a grade?
}

\author{
Sheila W. Valencia \\ University of Washington, Seattle, USA \\ Karen K. Wixson \\ University of Michigan, Ann Arbor, USA
}

I

$\mathrm{n}$ an Education Week essay on the politics and logistics of standards called, "Four Reasons Why Most 'Don't Cut the Mustard,'" Finn, Petrilli, and Vanourek (1998a) wrote as follows:

Millions of students, teachers, and parents are grappling this fall with new or changing state academic standards. In most cases, students, schools, and teachers will be judged by test scores keyed to these standards. Curricula will be revised. Some students may be held back. Perhaps a few teachers won't be rehired. Parents will have a yardstick by which to measure their kids' progress. All as a result of these standards.

"Fantastic!" we say, that's what standards-based reform is all about.

"Wrong," we say. This is not what standards-based reform is all about. It's part of the story, for sure, but this view doesn't capture the original intent of the reform. Standards-based reform is about creating a set of challenging standards for student performance and helping all students meet them, regardless of the students' heritage, socioeconomic status, or where they attend school. It includes assessments that are aligned with these standards so that students, parents, educators, and the public can monitor progress and provide assistance as needed. Although there has always been debate about the role of high-stakes assessment in this vision of reform (e.g., Linn, 1998; Smith, 1991), some form of accountability has always been involved as well. When accompanied by standards and aligned assessments, accountability focuses on outcomes rather than procedures or regulations, and it helps direct resources (fiscal, human, social) toward those outcomes.

Under this original vision of standards-based reform (National Council on Education Standards and Testing, 1992), schools and teachers were to be provided with flexibility to make the instructional, structural, and fiscal changes they determined were needed to achieve the standards. How they got there was their choice; getting to a common there was the key. If all the pieces were in place-standards, assessments, accountability, and flexibility - teaching and learning were expected to improve. Unfortunately, this vision of standards-based reform has been lost in the rush for quick fixes and obscured by competing political and educational agendas.

The entire reform effort, and the English/language arts standards in particular, has been consumed by debate. Everyone from liberals to conservatives wants to stake out a position, and both economic and educational cards have been played (Gratz, 2000). After 8 years of this wrangling, you might think that we could get on with the business of using standards to improve teaching and learning. But it doesn't seem so. 
A good example of how we have lost our way is the grading and rating frenzy that has besieged standardsbased reform. Four private groups have used their own criteria to evaluate state standards: the American Federation of Teachers (AFT), the Fordham Foundation, the Council for Basic Education (CBE), and Achieve. These education interest groups publicly rated the state standards, striving for a kind of meta-evaluation across the states. Unlike other reports on education that are written and summarily dismissed, these reports have received considerable media attention and have exerted enormous influence on states' reform efforts. For example, AFT reported that the year after they released their 1996 report card on standards, 39 states drafted new or revised standards. Achieve, an organization created by state governors and national business leaders to provide public leadership in support of standards-based reform, used the results of the other organizations' reports to help identify model standards against which every other state would be compared. These are reports with teeth!

We predict that this is not the last we'll see of such attempts to evaluate state standards activities and that other aspects of standards-based reform will similarly be subjected to review and evaluation by a variety of stakeholders. We are not, in principle, opposed to sharing and comparing standards across states; this can be a productive way to learn from one another. We worry, however, that the current attention to rating and grading is turning the elements of standards-based reform into high-stakes activities, diverting the original goal of improved teaching and learning to one of making the grade. We worry too, about the unexamined acceptance of such grades and the aura of objectivity they somehow convey.

The inconsistencies across reports belie their apparent objectivity and make the results confusing and frustrating to states and teachers, not to mention policy makers and public-education watchers. For example, in English/language arts, Michigan received an $\mathrm{F}$ from Fordham and a B+ from CBE. New York received a C from Fordham, the highest rating from AFT, and a B from CBE. In an odd twist, Connecticut, the state with the highest NAEP reading scores in the U.S., and the state cited as making the most progress in reading achievement since 1992 (Baron, 1999), received the lowest possible rating from AFT! In a response to AFT, the Connecticut Associate Commissioner of Education wrote, "Isn't it odd that our students should be doing so well and yet your ranking indicated a less than positive review of the standards we use" (American Federation of Teachers, 1999).

The confusion has found its way into the political arena as well. During the 1997 gubernatorial race in New Jersey, Senator McGreevey, the Democratic contender, cited two of the reports as proof that New Jersey's stan- dards were the "worst in the nation." Republican Governor Christine Todd Whitman cited a different report as proof that New Jersey standards and assessments were in the top five in the nation (Olson, 1998).

What are we to make of this? As Matt Gandal (formerly with AFT, now with Achieve) said, "It would take a lot of work for somebody in a state to try to figure out the different criteria at work here" (Olson, 1998). Certainly one explanation is that the various groups used different criteria. That is true, and it is important. But such an explanation makes it easy to dismiss the differences and let the politicians and the public choose whichever grade suits their purposes. The result can be political dynamite and educational turmoil. More important, rather than simply reflecting different criteria, we believe these ratings reflect deeper, much less obvious ideological and political beliefs.

Here, we use the recent evaluations of English/language arts standards by the organizations mentioned above to make three points. First, we argue that these types of evaluations, these efforts to grade, are not nonpartisan. Consumers at all levels-educators, policy makers, parents, and citizens-should recognize and understand the basic beliefs of those who issue these reports and whose voices are gaining power in political and education circles. Specifically, we need to understand the vision of standards, language arts, and language arts curriculum and instruction, and the view of the role standards play in education that underlie these reports. Second, we argue that such activities are unlikely to move us forward in our quest for standards-based reform. In fact, they may misdirect our attention and resources from where they are needed most. Finally, we argue that, armed with this knowledge, educators must become a force in standards-based reform.

\section{Background}

A little background will give some context for the standards movement and the rating and grading activities. The initial waves of reform in the 1980s focused on initiatives such as school restructuring and expanded assessment practices (Lusi, 1997). When these waves produced disappointing results, President Bush and the nation's governors called an education summit at which they agreed on six broad goals for education to be reached by the year 2000. In pursuit of the National Education Goals, the U.S. Congress established the bipartisan National Council on Education Standards and Testing (NCEST), which in 1992 reported that national standards and tests were both feasible and desirable. NCEST also explicitly addressed opportunity to learn, clearly acknowledging the importance of providing students not only with stan- 
dards and assessments but also with high-quality instruction. The logic was that once there was broad agreement on what students should know and be able to do, then everything else in the system (i.e., assessments, professional development, materials, school structures) could be directed toward achieving these standards. It was a systemic approach that included all elements rather than the piecemeal approach of the past.

The standards movement captured everyone's attention, certainly policy makers and the public, both of whom were concerned about student achievement and the skills of the work force. Educators, too, were interested, tired of assessments that didn't align with what they were teaching and concerned about the growing number of at-risk students in their classes. Over the next several years, pressure mounted for national standards and for states to develop or revise existing standards and to put into place assessments that were aligned to them. Although the national effort to develop English/language arts standards ran into difficulty both within and outside the literacy community (Pearson, 1998a, 1998b; Shannon, 1996), by 199949 of the 50 states had content standards for English/language arts. Meanwhile, the pressure had shifted away from simply having standards to judging their quality.

Perhaps what most pushed the quality issue of the English/language arts standards to center stage was the California story (McGill-Franzen, 2000). California was out in front of educational reforms in the 1980s, adopting a constructivist language arts framework, developing and aligning performance assessments, and establishing professional development networks. Yet National Assessment of Education Progress reading achievement results in 1992 and 1994 placed California students near the bottom in the nation. Although the debate continues about what role, if any, the California Language Arts Framework played in the decline in test scores (Chrispeels, 1997; McQuillan, 1998), the response to the results was a sharp indictment of the California framework. The criticism spurred a back-to-the-basics movement that added fuel to the educational and political rivalries that have long accompanied ideologies about beginning reading. On the heels of this came the evaluation of state standards.

We now move to a critical policy analysis of sorts (Edmondson, 2000) to examine the mission and composition of each organization, the process used to evaluate the standards, the criteria used, several examples provided in the documents, and some of the overall findings. Our purpose is not to conduct an in-depth analysis of the reports or to grade the graders. Rather, we use this analysis to illustrate the underlying educational, ideological, and political perspectives present in the various efforts to evaluate aspects of the standards movement. Although we realize that selective citing is risky, we nonetheless try to highlight exemplars of what we believe represent the thinking of each group. We realize, too, that we conduct this review through our own lenses on standards and English/ language arts; while we try to present the facts as we see them, we know others may see them differently. Moreover, although we worked with the most current documents we found, we are well aware that the ground-standards, organizations, political and educational affiliations and perspectives-is shifting as we write.

\section{The reports}

\section{American Federation of Teachers}

The American Federation of Teachers (www.aft.org) is an affiliate of the American Federation of LaborCongress of Industrial Organizations (AFL-CIO) and is the second largest teachers' union in the U.S. with over 1 million members. It sees itself as a major force for "preserving and strengthening America's democratic commitment to public education and public service." Over the years, AFT has supported desegregation, the Elementary and Secondary Education Act, better pay and working conditions for teachers, high academic standards and rigorous curricula, and higher standards for teacher certification. AFT supports charter schools, but not vouchers. It is proud of the fact that, after education came under attack in A Nation at Risk (National Commission on Excellence in Education, 1983), its president, Albert Shanker, publicly agreed with the report and asked AFT members to take charge of their profession.

AFT has produced an evaluation of standards every year since 1995. The author of the 1999 AFT document is Heidi Glidden of the Educational Issues Department of AFT. Several other people are acknowledged in the document, all of whom work for AFT; no people outside AFT are named as consultants or reviewers. The AFT criteria focused on two issues, both stated in generic terms so they could apply to four core subject areas: English, math, science, and social studies. The two issues are first, does the state have, or is it in the process of developing, standards in the four core academic subjects? Second, are the standards clear and specific enough to provide the basis for a common core curriculum from elementary through high school? (See Appendix A.) The standards were judged for all 50 states at elementary, middle, and high school levels. AFT used a check mark to indicate that the criteria were met instead of assigning a grade; however, Education Week (2000) took AFT's evaluations and assigned grades. 
AFT's desire for specificity favored a fairly explicit level of detail at the state level. For example, it preferred state standards that were grade by grade rather than grade bands, arguing that it was easier to assure consistency from grade to grade and easier to align curriculum, assessments, textbooks, and instruction. AFT looked for articulation and increasing levels of complexity of the standards across grade level. It did not accept standards that were the same across grades even if there was a reference to grade-appropriate level; grade-appropriate level needed to be defined in specific terms as did the specific skills students must demonstrate.

The 1999 AFT report also included analyses of several additional state reform efforts (assessments, consequences attached to standards, and intervention for struggling students). AFT believed that without these additional systems of support, "it is doubtful that even the best standards will have much impact on student achievement." Accordingly, it included all the evaluations in the same report. AFT's emphasis on specificity, and we would suggest, control, was also evident in some of the criteria related to assessment. For example, AFT supported testing every student by the state (with standardsbased assessments), asserting that it is the responsibility of the state, and that districts don't have the resources to assure high-quality assessment. Similarly, it wanted states to have both graduation exams and promotion (at specified grades) tied to state standards and assessments. This level of control has been rejected by some state leaders (see Diegmueller, 1996) who don't believe states should dictate curriculum, yet AFT clearly wanted fewer choices left to local control. On the surface, we might imagine that a teachers' union would not support such a high degree of external control, yet some suggest this is a way to protect teachers-it leaves no question about what they are supposed to be teaching. With curriculum defined, according to an AFT spokesperson, teachers could have flexibility in the way they teach (Diegmueller, 1996).

In line with its emphasis on clarity and specificity, AFT took a strong position that the standards should define both the content and the skills students should learn in each of the core subjects. To help identify particular content for each subject area, AFT reviewed content-related documents. In English, it reviewed a set of documents representing a variety of perspectives: NAEP reading and writing frameworks (National Assessment Governing Board, n.d.), Every Child Reading: An Action Plan (Learning First Alliance, 1998), and Core Knowledge Sequence: Content Guidelines for Grades K-8 (Core Knowledge Foundation, 1998). AFT concluded that

The consensus in the various documents on English language arts indicates that English standards should address the basic skills and knowledge that are the foundation of learning how to read (e.g., letter-sound recognition, decoding skills, and vocabulary), reading comprehension (e.g., exposure to a variety of literary genres) and writing conventions (e.g., spelling, writing mechanics), and writing forms (e.g., narrative, persuasive, expository). In laying out these standards, it is important for a state to indicate in which grades or clusters key elements will be taught.

This combination of emphasis on specificity and content was evident in AFT's specific state-by-state evaluations and in the narrative documentation that accompanied the standards. A few examples make AFT's perspective clear. One state, for example, was cited as providing good specificity for students in first grade who should be able to

spell single words that have $r$-controlled vowels such as in burn or star; that have the final consonants $f, l$, and $s$ such as in miss or doll; and that have $c k$ as the final consonant such as in buck.

Another state required third graders to

identify and interpret elements of fiction and nonfiction and support by referencing the text to determine the: author's purpose, plot, conflict, sequence, resolution, lesson and/or message, main idea and supporting details, cause and effect, fact and opinion, point of view (author and character), [and] author's use of figurative language (e.g., simile, metaphor, imagery).

In contrast, another state was found to have vague standards such as having early elementary students "read with a developing fluency a variety of texts such as stories, poems, messages, menus, and directions." AFT was concerned that this standard neither defined developing fluency nor provided guidance on the specific reading knowledge and skills early elementary students need to develop into proficient readers. Similarly, having students "identify the characteristics of literary forms and genres" was considered too vague because it didn't define the specific characteristics.

Even with this level of specificity and attention to content, AFT was clear that it was not judging the quality or rigor of the content covered. For example, it wouldn't determine if particular editing skills listed for middle school were appropriate. Furthermore, although AFT did want the level or the specific skills defined, it did not want a "laundry list of concepts and skills in order to 'cover' everything." However, in our view, in order to achieve the specificity AFT wanted, the standards it endorsed were often list-like.

As we might suspect, AFT concluded that the states' English standards are weak; only 21 met the criteria at all three levels. Although more states passed at the elementary level, AFT's only specific recommendation in English 
was that states increase attention to $\mathrm{K}-3$ reading basics, to "include specific guidance on the basic knowledge and skills students should learn to develop into proficient readers." No doubt, this reflects the current debate regarding early reading instruction.

\section{The Fordham Foundation}

The Fordham Foundation (www.edexcellence.net) was founded in 1953. In 1995 it turned its focus entirely to the reform of elementary and secondary education. In 1996 Chester Finn, former assistant Secretary of Education in the Reagan administration, became the Foundation's president and chief executive officer. The Foundation has assumed primary sponsorship of the Educational Excellence Network (EEN), a 15-year-old organization founded by Finn and Diane Ravitch that is committed to "high standards, strong academic content and tough-minded accountability." EEN supports the "reinvention" of K-12 education including "charter schools, contract-management, scholarships, and other strategies for stimulating more education choices." They clearly support alternatives to public education and what they call "consumer empowerment." The Fordham Foundation is also affiliated with the Manhattan Institute, a conservative think tank in New York.

It appears that Fordham's funding comes only from money left by Thelma Fordham Pruett. No other funders are mentioned. Its six-person board is composed of representatives from law, business, foundations, and higher education. Its mission includes making grants to advance educational activities, providing scholarship assistance for students, and engaging in, sponsoring, and publishing results of research. It has assumed many of the reform strategies and principles advanced by EEN. These include high academic standards, verifiable accountability, core curriculum, choice, and dissemination of "sound research." The Foundation does not support unsolicited projects; it seeks out projects and individuals that "go against the grain, challenge the received wisdom, alter the status quo, and work outside the box." All quotes can be found on Fordham website.

Fordham set out to determine "just how good state academic standards are today," if they are likely to boost achievement if implemented, and if they point schools in the "right direction" in English, math, science, history, and geography. The criteria for evaluation of the English standards were developed by Sandra Stotsky of Harvard and Boston Universities who is currently Associate Commissioner of Education for the Massachusetts Department of Education. She consulted with three other educators (James Squire, Richard Larson, and Allan Glatthorn) "as she saw fit." Stotsky then evaluated standards from 28 states_-22 that were approved by AFT plus the most populous states and a few that hadn't been approved by AFT. Only one state received an A from Fordham-Massachusetts; Stotsky was the cochair of the committee that rewrote the Massachusetts English standards.

Two documents were helpful for understanding the beliefs and values implied in Fordham's criteria: Stotsky's rationale for each criterion along with her detailed evaluation for each state (Stotsky, 1997), and Finn, Petrilli, and Vanourek's summary, The State of State Standards (1998b). The criteria were not presented by grade level, although Fordham wanted states to have standards grade by grade or in clusters of no more than three to four grade levels. There were five major categories for evaluation. One of these, Anti-Literary or Anti-Academic, is a negative category in which states lost points for meeting the related seven criteria (see Appendix B).

Several points distinguished the Fordham criteria. First, we found a clear statement about the use of the English language - that encouraging students to use their home language, if different from English, in the English class "retards" the students' acquisition of English and "consumes valuable time" of the English-speaking students.

Second, several criteria suggested a canon of English literature and an expectation that the quantity and quality of independent reading should be specified. Stotsky (1997) looked for standards that acknowledged a body of work called "American literature" and for reference to specific literary movements that students need to read and know. Similarly, she argued against choosing literature that addresses contemporary social issues because it eliminates other literature from the curriculum and may "dumb down" the curriculum with poor quality books. In Finn et al.'s (1998b) terms, such standards are "hostile to knowledge."

Third, Fordham wanted standards to be "measurable, leading to observable, comparable results across students and schools." This criterion meant that strategies, processes, and values were kept out of the standards because they were "unlikely to be measurable." For example, Stotsky (1997) wrote, "How can one know what strategies or how many strategies students use when they 'employ multiple strategies to construct meaning while reading."

Fourth, under the Anti-Literary or Anti-Academic heading we found strong objection to having students relate reading to their own lives and cautions about personal response and multiple interpretations of text. Stotsky (1997) didn't object to asking K-2 students to relate reading to their lives nor did she object to standards that "allow" students to bring personal experience to bear. However, she was adamant about requiring students at 
higher grade levels to do so. She noted that "to require students at higher educational levels to read their lives into the literature they are asked to study undermines the very capacity of a literary work to help readers transcend their limited experiences." According to Stotsky,

[R]equiring personal application of literary understandings is also fraught with hazard. There are examples of lovestruck adolescents who have read Romeo and Juliet and then attempted to apply the characters' 'solution' to their lives because their parents objected to their relationship. Students may bring misunderstood ideas as well as bad ideas in what they read to their own or others' lives. Such standards encourage an irresponsible and potentially dangerous pedagogy.

Finally, Fordham, like the other groups we examined, asserted that standards shouldn't prescribe teaching methods or pedagogical strategies - that no single approach can meet all students' needs. It endorsed teacher decision making. Yet, Fordham seemed fairly strongminded with respect to particular approaches. On one hand, for example, in a negative review of one state's standards, Stotsky (1997) wrote, "The document is heavily oriented to a process approach for reading and writing, to a reader response approach for literary study, to learning all skills in context, and to a focus on students' values and attitudes." She objected to the position statements in the document that promoted a variety of "trendy pedagogical ideas." On the other hand, one Fordham criterion called for "explicit and systematic instruction in decoding skills in the primary grades as well as the use of meaningful reading materials." Further, the report elaborated:

Nor is it enough to provide phonics instruction only in the context of a story they are reading; students need to practice applying decoding skills to isolated decodable words and then to some texts with mostly decodable words so they learn how to identify words in context without having to be dependent on context clues.

This is not a neutral pedagogical stance.

Additional insight into the beliefs that underlie the Fordham perspective on English standards was revealed in Finn et al.'s (1998b) portrayal of constructivism as a throwback to the 19th-century interest in thinking without regard for content. They characterized today's constructivism as a belief that "students should be allowed to learn what they want to learn," a "replacement of cultural content with the "mastery' of skills." This perspective on English/language arts standards is in direct contrast to the AFT emphasis on skills and processes at the expense of the "cultural" content embodied in literature.

\section{Council for Basic Education}

The Council for Basic Education (www.c-b-e.org) was founded in 1956 by a group of "concerned citizens" with a commitment to "the relationship between a healthy democracy and excellence in public education." Its stated mission is "to strengthen teaching and learning of the basic subjects, (English, history, government, geography, mathematics, the sciences, foreign languages, and the arts) in order to develop the capacity for lifelong learning and foster responsible citizenship." CBE's definition of basic subjects clearly goes beyond what AFT and Fordham consider core. CBE sees itself as an "independent critical voice for education reform" and advocates its positions through publications and practical programs to strengthen content in curriculum and in teaching. Its 18member board of directors comprises primarily corporate executives, former U.S. Congressional representatives, and educators. Its President, Christopher Cross, served as Assistant Secretary for Educational Research and Improvement in the Reagan administration and as Director of the Education Initiative of the Business Roundtable.

CBE receives its funding from a wide variety of foundations, corporations, and public agencies including The Pew Charitable Trust, National Endowment for the Humanities, Ford Foundation, the U.S. Department of Education, and many state departments of education. It has a variety of projects including fellowships programs for teachers and principals, technical assistance to school districts and states, and collaborations with the American Association of Colleges of Teacher Education (AACTE) (to develop several models of standards-based teacher education programs) and the Association for Supervision and Curriculum Development (ASCD) (to market a kit of Standards for Excellence in Education). In 1998

Education Week asked CBE to evaluate the rigor of state standards because it wanted an evaluation for its "Quality Counts" series that went beyond the AFT criteria of clarity and specificity. Since that time, however, CBE has discontinued its rating of state standards to focus on providing technical assistance to states and local school districts on standards development and implementation (Jerald, Curran, \& Boser, 1999).

The analysis CBE conducted was designed solely to examine the rigor of state standards. It did, however, acknowledge the importance of specificity, clarity, and organization, and the confounding effects these qualities have on judging rigor. In some ways, because CBE used specific benchmarks for Grades 4 and 12, some level of specificity was built into their system. Nevertheless, it seemed not to want or need the level of specificity, or control, of either AFT or Fordham. 
CBE wanted an evaluation process that was "fair, reliable, analytical, and explicit, and therefore replicable and informative." Unlike AFT and Fordham, CBE used an advisory panel of subject specialists, teachers, parents, and business representatives to review its definition of rigor, framework benchmarks (model standards for Grades 4 and 12), and rubrics. (CBE advisors were Cleve Bryant, Ruth Dennis, Alan Farstrup, Bonnie Hain, Craig Jerald, Gene Kijowski, Louisa Moats, and Shirley Nelson.) Then CBE provided in-depth training to a team of evaluators, all experienced English/language arts teachers, who independently evaluated state standards against the model set. CBE evaluators rated all of the states that had approved English standards. The grades were published in the report, but individual evaluations were privately sent to the states. As a result, we didn't have many examples of the thinking behind their grades; we had to depend on the definitions, specific framework benchmarks, general findings, and examples in their document to understand how the frameworks were interpreted and what characteristics were most important to this group.

CBE's definition of rigor in English/language arts stated that "the standards should require all students, at the appropriate grade level, to learn the essential concepts and skills of English language arts at the level of sophistication specified by the Council for Basic Education's Standards for Excellence in Education (SEE), which were written in consultation with subject experts who drew inspiration from exemplary state and national standards documents" (Joftus \& Berman, p. 9). SEE was a CBE project, initiated in July 1995 to create model standards for each content area; the English/language arts portion of this document served as the framework for the CBE standards evaluation process (see Appendix C). What was apparent from the definition of rigor and a review of the framework with its many "e.g." and "such as" notations was that CBE did not attempt to be prescriptive. In fact, it stated that "standards must be clear and specific but without dictating instructional practice" (p. 9). This message was also apparent from phrases such as "many genres," revision based on "established criteria," "read aloud with accuracy, fluency, and comprehension," and "read to perform a task" included in the benchmarks.

The concepts and skills that actually appeared in the benchmarks reflected a combination of traditional skills (e.g., phonics, fact and opinion, organizing information, figurative language) and processes (e.g., comprehension strategies, writing process, listen critically). Furthermore, CBE valued personal response to literature and an understanding of values and the aesthetic dimensions of text. Although it acknowledged the importance of decoding and word attack skills, CBE did so in broader statements related to reading with accuracy, fluency, and comprehension. Because CBE intentionally elected not to evaluate standards below the fourth grade, the debate concerning phonics didn't play a large role." It chose to stay out of this arena, yet in the report CBE authors "acknowledge the importance of providing all children with phonemic based reading strategies, as many studies have shown that this approach, in conjunction with others, works best for most students."

The one area in English/language arts where specificity seemed of major importance for $\mathrm{CBE}$ was in what it called the read a lot benchmarks that specified the number of books students should read. CBE criticized states for not specifying the quality and quantity of texts students read, and it raised concerns about the difficulty level of those texts (as did all the other reports). CBE wrote, "using language such as, 'Students read appropriate texts at appropriate levels,' provides a very weak guide for teachers" (p. 15). Although it didn't include a suggested author list in the benchmarks, CBE concluded that it should provide one in their new SEE document. Clearly, CBE was not willing to let difficulty level remain unspecified. Like the other groups, CBE wanted to provide guidelines for quantity, difficulty, and quality; but unlike Fordham, CBE did not want a prescribed canon.

Unlike the substantial number of poor scores given by Fordham and AFT, CBE found more than two thirds of the states had rigorous or very rigorous English/language arts standards. It found that most did a good job of addressing basic skills. When states didn't pass, they simply lacked several of the required concepts and skillsspecifically amount and quality of reading, study of a range of literary genres, research skills, and language study. CBE suggested that these missing areas should be addressed, and it conjectured that these gaps might have been a result of states not having a recognized national model for English/language arts standards.

\section{Achieve}

Achieve (www.achieve.org) was founded by governors and corporate leaders after the 1996 National Education Summit. By its own description, Achieve is a bipartisan, nonprofit organization governed by a board of six governors and six corporate leaders. One of its three stated purposes is "to help states benchmark their academic standards and assessments against the best national and international exemplars, and to provide advice and assistance to states on implementation strategies." Achieve also maintains that states deserve high-quality information about their standards and do not yet have it, in part because the movement is in its infancy and in part because of the disparate nature of the other evaluation efforts. Its documents state the following: 
Other organizations that issue standards reviews and "report cards" have helped focus national attention on the quality of standards, but these judgments often have conflicted, and their tone has not always been constructive. States increasingly are looking for independent, credible advice on their issues. (Achieve, 2000, p. 6)

So, in 1998, fully aware of the rating muddle, Achieve decided to step in. It does not intend to rank or grade states' standards but to provide information to states that contract and pay a fee for their help as they pursue standards-based reform in English/language arts and mathematics. Thus far, Achieve has published reports on four states, and it is in various stages of the benchmarking process with approximately five others.

Currently, Achieve offers states several benchmarking services: (a) reviews of standards, (b) comparisons of standards to other states' and nations' standards, (c) assessment of alignment of standards and assessments, and (d) assessment of test and textbook alignment. To develop their procedures, Achieve contracted with CBE and the Learning Research and Development Center (LRDC) at the University of Pittsburgh to conduct two pilot studies on the design and implementation of standards and assessment benchmarking. In light of the pilot data, the procedures were refined to include three general steps. First, Achieve presented a group of bipartisan content area experts with a packet of information about the state standards to be reviewed. In the packet were the actual standards, comments including an overview of the standards' structure and basic observations, and a chart that used universal topical organizers to place the state standards under review side-by-side with the benchmark standards (standards from specific states that were identified as exemplars). Then the experts analyzed these materials on their own by reacting to questions focused on clarity and accessibility, measurability, comprehensiveness and focus, balance, and rigor (see Appendix D). Finally, the reviewers came together to develop consensus evaluations.

Like CBE, Achieve developed an extensive evaluation process. Yet, just as with the other organizations, its efforts reflect a particular view of the role of standards in general and of the domain of English/language arts in particular. This is apparent in the description of Achieve's criteria: "Standards... must be specific enough about content to provide guidance to teachers as they develop lessons, to parents as they guide students' learning, and to curriculum and test developers who write standardsbased materials and tests." As an example, Achieve suggests that "'Read for enjoyment' is virtually impossible to assess, while 'Define a simile and analyze its impact on a selection' is much more clear and measurable." The view of standards advanced by Achieve's criteria and methods was that they should be sufficiently specific to be measurable.

Achieve selected the benchmark standards for English/language arts by asking experts to evaluate five sets of English/language arts standards: California, Massachusetts, NAEP Reading Framework, NAEP Writing Framework, and New Standards Performance Standards. The published materials do not indicate how these five were selected or who examined them. However, given this set of five and Achieve's benchmarking goals, it is not surprising that only the two state documents in the pool (California and Massachusetts) were specific enough to be chosen as the benchmark standards documents. Although Achieve examined how these two benchmark documents fared in the AFT, CBE, and Fordham evaluations as a check on their selection, we noted connections among these various evaluations. Specifically, as we noted earlier, the individual who conducted the Fordham evaluation played a key role in the development of the Massachusetts standards and then became a standards expert for Achieve. In addition, the individual responsible for the AFT evaluation recently assumed a leadership role in Achieve.

The choice of California and Massachusetts as the benchmark standards documents for English/language arts has had a significant effect on the results of the Achieve benchmarking process. Because California's standards are probably the most detailed in the nation, state standards that have been reviewed have not compared favorably in terms of specificity. The Massachusetts standards reflect some of the biases evident in the Fordham report - the only state to receive an A from Fordham. Furthermore, the influence of both these documents has, no doubt, been heightened by the participation of the author of the Fordham report and several individuals involved in the development of the California standards who are among the experts who participated in Achieve's standards benchmarking. (Achieve's experts included Sheila Byrd, Carol Jago, Louisa Moats, Sandra Stotsky, and Karen Wixson.)

After Achieve's initial round of evaluations, it continued to evaluate its choices of both benchmark standards documents and benchmarking procedures. After additional expert reviews and pilot studies, Achieve decided to use North Carolina and Texas as the benchmark standards documents for early literacy standards and has subsequently decided to reexamine its selection and use of benchmark standards in English/language arts. It has also continued to recruit experts who represent a variety of perspectives to participate in its benchmarking activities in an effort to avoid advancing any particular ideological stance (J. Vranek, personal communication, July 
26, 2000). This is important because, if our predictions about future grading and rating activities are accurate, the types of alignment evaluations conducted by Achieve may become the next high-stakes activity in standardsbased reform.

\section{Conclusions}

Our goal here was to use the example of grading and rating standards to make clear the ideological and political backdrop of standards-based reform in the United States. Beneath the rhetoric of the evaluation frenzy are fundamental beliefs about the role of standards and the nature of English/language arts and its instruction. It is impossible to summarize neatly the perspective of each organization, but it is clear, in our view, that each has a different stance on these issues. Some believe standards should be so specific as to lead schools to a core curriculum; others see standards as distinct from curriculum. Some define the content of English/language arts in terms of processes and skills; others come closer to a canon. Some accept process approaches to reading and writing; others do not. Some are tied to measurable outcomes; others include standards that may be difficult to measure in a state assessment. We could go on. In sum, it is naive and risky to accept these reports at face value.

There are also similarities in the reports that are instructive and worth noting (Olson, 1999). But we fear that looking for the common denominators may lead states down the wrong road. The path to getting a high grade from all of these groups is to go for the greatest level of specificity and the most tightly constructed definition of English/language arts. This is not a neutral stance, nor is it a compromise strategy. Rather, it is one that favors and forces a particular position. On this point of ideological perspective, we agree with Finn et al. (1998b):

[I]t's important to guard against politicization in academic standards, especially those meant to apply to all the schools and school children in an entire state. Standards are benchmarks for what students should know and be able to do, and it is unconscionable to use them as political or ideological tools (or weapons).

We conclude that there has been an inordinate and inappropriate amount of attention, time, and resources devoted to this metalevel of standards evaluation and to the kind of fix-ups and jockeying for position that have resulted. Certainly, it is helpful to engage in cross-state conversations, to go beyond provincial, idiosyncratic views of what is possible. But to focus on grading and rating seems to us to go beyond what is helpful. Some suggest this quest for comparisons is motivated by genuine concern for high standards for all students. Others suggest the motivation may be more political: an effort to prove what the public already fears, that public education isn't working, to gain support for vouchers and home schooling, and to provide easy platforms for politicians (Cross, 1998; Gratz, 2000). Equally disconcerting is the endless cycle of refining or perfecting standards that results from such reports. Is this how student achievement will improve? Is this the road to better teaching and learning? Is this where our limited resources should be spent? We think not.

Research and experience suggest that more time on standards and assessment alone will not improve learning. What is needed is a direct link between the components of standards-based reform (i.e., standards, assessments, accountability, and flexibility) and instructional improvement strategies. And this difficult, longterm work on teaching and learning can only happen at the local level with appropriate guidance and support from the state. We agree with the National Research Council (1999) and the consensus report of the Council of Chief State School Officers (1996) that standards should offer midrange advice, specific enough to ensure that both curricula and assessments will work toward a common destination but broad enough to accommodate a wide range of strategies to fit different contexts. Then the real work of standards-based reform can happen at the local level.

Discussion is at the heart of local understanding and implementation of standards. The process of having teachers, parents, community, and business groups think together about what they want in their standards helps to bring previously unexamined expectations to light and provides opportunities to clarify, as a community, what is important. It provides a way to honor both a national vision and local knowledge-to value the tension between the two that resides in a healthy democracy so that no one organization, person, or perspective assumes authority for deciding what matters (Gutmann, 1999; Pearson, 1998a, 1998b). Furthermore, conversation can be a gateway for professional development programs that target improved instruction. Not surprisingly, as energy is directed to these issues of implementation, we will be thrust back into discussions of standards, assessment, and accountability, proving the point that standards-based reform is an iterative not linear process in which all the pieces must be juggled simultaneously. Standards documents should always be works in progress.

What are we educators to do in this time of standards-based reform? In our view, standards-based reform is a worthwhile endeavor - a way to address inequities of the past and raise the ceiling for all. Standards-based reform deserves our attention, our knowledge, and our energy. If standards-based reform is to achieve its potential, 
we must participate in the discussions and sponsor them where they are absent. We must bring multiple perspectives to bear on the issues and help bring to the surface the political agendas that lie beneath. And we need to insert our professional knowledge into debates that often lack precisely that. But perhaps our most important contribution would be to add a badly needed measure of sobriety to what we have been calling the frenzy. We must counter the demands for quick fixes and challenge the conclusions of those who are eager to pass judgment. We must slow down, take a breath, and remember why standards-based reform came to be.

\section{REFERENCES}

ACHIEVE. (n.d.). [Online]. Available: www.achieve.org

ACHIEVE. (2000). Measuring up. A report on education standards and assessments for Indiana. Washington, DC: Author.

AMERICAN FEDERATION OF TEACHERS. (1999). Making standards matter 1999. Washington DC: American Federation of Teachers [Online]. Available: www.aft.org/edissues/standards99

BARON, J.B. (1999). Exploring high and improving reading achievement in Connecticut. Washington, DC: National Education Goals Panel.

CHRISPEELS, J.H. (1997). Educational policy implementation in a shifting political climate: The California experience. American Educational Research Journal, 34, 453-481.

CORE KNOWLEDGE FOUNDATION. (1998). Core knowledge sequence: Content guidelines for grades $K-8$. Charlottesville, VA: Author. COUNCIL FOR BASIC EDUCATION. (n.d.). [Online]. Available: $\underline{w w w}$. c-b-e.org

COUNCIL OF CHIEF STATE SCHOOL OFFICERS. (1996). Criteria for standards. Washington, DC: Author.

CROSS, C. (1998, October 21). The standards wars: Some lessons learned. Education Week on the Web [Online]. Available:

www.edweek.org/ew/1998/08cross.h18

DIEGMUELLER, K. (1996, August 7). By AFT's standards, only 15 states deserve passing grade. Education Week on the Web [Online]. Available: www.edweek.org.ew/vol-15/41stand.h15

EDMONDSON, J. (2000). America Reads: A critical policy analysis.

Newark, DE: International Reading Association.

EDUCATION WEEK. (2000, January 13). Quality counts, 2000. Education Week, 19(18), 84.

FINN, C.E., JR., PETRILLI, M.J., \& VANOUREK, G. (1998a, November 11).

Four reasons why most 'don't cut the mustard.' Education Week on the Web

[Online]. Available: www.edweek. org/ew/vol-18/11 finn.h18

FINN, C.E., JR., PETRILLI, M.J., \& VANOUREK, G. (1998b). The state of state standards. Fordham Report, Vol. 2, No. 5 [Online]. Available: www.edex cellence.net/standards

GRATZ, D.B. (2000). High standards for whom? Phi Delta Kappan, 81, $681-687$

GUTMANN, A. (1999). Democratic education (2nd ed.) Princeton, NJ:
Princeton University Press.

JERALD, C.D., CURRAN, B.K., \& BOSER, U. (1999, January 11). State of the states: Quality counts '99. Education Week, 18(17), 106.

JOFTUS, S., \& BERMAN, I. (1998). Great expectations? Defining and assessing rigor in state standards for mathematics and English language arts. Washington, DC: Council for Basic Education.

LEARNING FIRST ALLIANCE. (1998). Every child reading: An action plan. American Educator, 22, 52-63.

LINN, R.L. (2000). Assessments and accountability. Educational

Researcher, 29, 4-16.

LUSI, S.F. (1997). The role of state departments of education in complex school reform. New York: Teachers College Press.

MCGILL-FRANZEN, A. (2000). Policy and instruction: What is the relationship? In M.L. Kamil, P.B. Mosenthal, P.D. Pearson, \& R. Barr (Eds.), Handbook of reading research: Volume III (pp. 889-908). Mahwah, NJ: Erlbaum.

MCQUILLAN, J. (1998). The literacy crisis: False claims, real solutions. Portsmouth, NH: Heinemann.

NATIONAL ASSESSMENT GOVERNING BOARD. (n.d.). Reading framework for the 1992 National Assessment of Educational Progress. Washington, DC: Author.

NATIONAL ASSESSMENT GOVERNING BOARD. (n.d.). Reading framework for the 1998 National Assessment of Educational Progress. Washington, DC: Author.

NATIONAL COMMISSION ON EXCELLENCE IN EDUCATION. (1983). A nation at risk: The imperative for educational reform. Washington, DC: U.S. Government Printing Office.

NATIONAL COUNCIL ON EDUCATION STANDARDS AND TESTING. (1992). Raising standards for American education. Washington, DC: U.S. Government Printing Office.

NATIONAL RESEARCH COUNCIL. (1999). Testing, teaching, and learning: A guide for states and school districts. Washington, DC: National Academy Press.

OLSON, L. (1998, April 15). An 'A' or a 'D': State rankings differ widely. Education Week on the Web [Online]. Available:www.edweek.org/ew/vol17/31stand.h17

OLSON, L. (1999, January 11). Rating the standards. Quality Counts '99. Education Week, 18(17), 107-109.

PEARSON, P.D. (1998a). Standards and assessments: Tools for crafting effective instruction? In J. Osborn \& F. Lehr (Eds.), Literacy for all, issues in teaching and learning (pp. 264-288). New York: Guilford Press.

PEARSON, P.D. (1998b). Standards in the language arts. In J. Flood, S. Brice-Heath, \& D. Lapp (Eds.), Handbook of research on teaching literacy through the communicative and visual arts (pp. 763-775). New York: Macmillan.

SHANNON, P. (1996). Mad as hell. Language Arts, 73, 14-19.

SMITH, M.L. (1991). Put to the test: The effects of external testing on teachers. Educational Researcher, 20(5), 8-11.

STOTSKY, S. (1997). State English standards. Fordham Report, Volume 1, No. 1 [Online]. Available: www.edexcellence.net/stotsky/

THOMAS B. FORDHAM FOUNDATION. (n.d.). [Online]. Available: www.edexcellence.net

Received August 7, 2000 Final revision received September 12, 2000 Accepted September 19, 2000 


\section{APPENDIX A}

Making Standards Matter 1999

American Federation of Teachers*

\section{Judging State Standards Reforms}

Issue 1: Does the state have, or is it in the process of developing, standards in the four core academic subjects-English, math, science, and social studies?

Issue 2: Are the standards clear and specific enough to provide the basis for a common core curriculum from elementary through high school?

1. Standards must define in every grade, or for selected clusters of grades, the common content and skills students should learn in each of the core subjects.

2. Standards must be detailed, explicit, and firmly rooted in the content of the subject area to lead to a common core curriculum.

3. For each of the four core curriculum areas, particular content must be present.

4. Standards must provide attention to both content and skills.

"From American Federation of Teachers (1999). 


\section{APPENDIX B}

\section{Fordham Foundation}

\section{State English Language-Arts/Reading Standards*}

\section{A. Purpose, audience, expectations, and assumptions of the standards document(s)}

1. The document is written in clear English prose, for the general public as well as educators.

2. It assumes that English is the language to be used in English language-arts classes, and the only language to be used.

3. It expects all students to demonstrate use of standard English, orally and in writing.

4. It acknowledges the existence of a corpus of literary works called American literature, however diverse its origins and the social groups it portrays.

5. It expects students to become literate American citizens.

6. It expects explicit and systematic instruction in decoding skills in the primary grades as well as the use of meaningful reading materials.

7. It expects students to do regular independent reading through the grades, suggesting how much reading students should do per year as a minimum, with some guidance about its quality.

8. It expects the standards to serve as the basis for clear and reliable statewide assessments.

\section{B. Organization of the standards}

1. They are presented grade by grade or in clusters of no more than 3 to 4 grade levels.

2. They are grouped in categories reflecting coherent bodies of scholarship or research in the English language arts.

3. They are distinguished higher-order knowledge and skills from lower-order skills, if lower-order skills are mentioned.

\section{Disciplinary coverage of the standards}

1. The standards clearly address listening and speaking. They include use of various discussion purposes and roles, how to participate in discussion, desirable qualities in formal speaking, and use of established as well as peer-generated or personal criteria for evaluating formal and informal speech.

2. The standards clearly address reading (and viewing) to understand and use information through the grades. They include progressive development of reading skills and a reading vocabulary, and knowledge and use of a variety of textual features, genres, and reading strategies for academic, occupational, and civic purposes.

3. The standards clearly address the reading (or viewing), interpretation, and critical evaluation of literature. They include knowledgeable or diverse literary elements and genres, different kinds of literary responses, and use of a variety of interpretive and critical lenses. They also specify those key authors, works, and literary traditions in American literature and in the literary and civic heritage of English-speaking people that all students should study because of their literary quality and cultural significance.

4. The standards clearly address writing for communication and personal expression. They require familiarity with writing processes, established as well as peer-generated or personal evaluation criteria, and various rhetorical elements, strategies, genres, and modes of organization.

5. The standards clearly address oral and written language conventions. They require the use of standard English conventions for sentence structure, spelling, usage, penmanship, capitalization, and punctuation.

6. The standards clearly address the nature, dynamics, and the history of the English language. They cover the nature of its vocabulary, its structure (grammar), the evolution of its oral and written forms, and the distinction between the variability of its oral forms and the relative permanence of its written form today.

7. The standards clearly address research processes, including developing questions and locating, understanding, evaluating, synthesizing, and using various sources of information for reading, writing, and speaking assignments. These sources include dictionaries, thesauruses, other reference materials, observations of empirical phenomena, interviews with informants, and computer data bases. 


\section{APPENDIX B}

Fordham Foundation*

State English Language-Arts/Reading Standards (continued)

\section{Quality of the standards}

1. They are clear.

2. They are specific.

3. They are measurable (i.e., they can lead to observable, comparable results across students and schools).

4. They are comprehensive.

5. They are demanding:

a. They are of increasing intellectual difficulty at each higher educational level and cover all important indices of learning in the area they address.

b. They index or illustrate growth through the grades for reading by referring to specific reading levels or to titles of specific literary or academic works as examples of a reading level.

c. They illustrate growth through the grades for writing with writing samples.

d. For the other subdisciplines, they provide examples of specific reading, writing, or oral language features, activities, or assignments that clarify what is expected for each standard or benchmark.

6. Their overall contents are sufficiently specific, comprehensive, and demanding to lead a common core of high academic expectations for all students in the state, no matter what school they attend.

\section{E. Anti-literary or anti-academic requirements or expectations: negative criteria}

1. The document implies that the literary or popular culture of our or any other country is monolithic in nature.

2. The reading/literature standards require students to relate what they read to their lived experiences.

3. The reading/literature standards want reading materials to address contemporary social issues.

4. The document implies that all literary and nonliterary texts are susceptible of an infinite number of interpretations and that all points of view or interpretations are equally valid regardless of the logic, accuracy, and adequacy of the supporting evidence.

5. The examples of classroom activities or student writing offered are politically slanted or reflect an attempt to manipulate students' feelings, thinking, or behavior.

6. The standards teach moral or social dogma.

7. The document explicitly or implicitly recommends one instructional approach for all teachers to follow.

*From Thomas B. Fordham Foundation (n.d.) 


\section{APPENDIX C \\ Council for Basic Education* \\ English Language Arts Framework}

\section{FOURTH GRADE}

I. Read fluently and critically for a variety of purposes; synthesize information from a wide range of sources, including a variety of media.

1. Read aloud independently with accuracy, fluency, and comprehension, using decoding and word attack skills (e.g., phonological awareness, phonic analysis, structural analysis) and comprehension strategies (e.g., inferencing; predicting, summarizing, and paraphrasing or retelling; generating questions; and identifying main ideas and details to support them).

2. Distinguish between fact and opinion and main ideas and supporting details to draw meaning from various texts and media presentations.

3. Read to perform a task and to gather information.

4. Compare messages and organization in reading and media selections and relate content and message to previous knowledge.

5. Identify basic visual media conventions, techniques, and processes used to support a variety of purposes (informational, inspirational, entertainment, manipulative); use media conventions and techniques to tell stories and communicate basic information.

II. Read a variety of texts of different types (e.g., fiction, autobiography, historical narratives) by different authors and on different subjects.

1. Read and comprehend the equivalent of at least 30 books per year in first through fourth grade of a specified variety in their entirety, both assigned in class and chosen for independent reading.

III. Recognize and write in a variety of forms (including narratives, journals, stories, poetry, articles, instructions, analytical essays) to effectively convey intended meaning to particular audiences.

1. Write for a specific purpose, audience, and context, using a simple organizing structure.

2. Support a central idea with relevant facts and details in simple paragraph form.

3. Recognize and employ the distinguishing features of different types of writing, such as instructions, narratives, journals, stories, poetry, drama, letters, news articles, and speeches.

4. Use key writing processes (with assistance), including prewriting, drafting, peer review, revising, editing, and publishing, to develop and express ideas.

IV. Communicate effectively, adjusting use of spoken and visual language to convey intended meaning to a particular audience.

1. Demonstrate oral language skills including pace, volume, emphasis, pronunciation, audibility, and appropriate choice of words.

2. Explain how verbal and nonverbal clues and variations in tone and gesture affect meaning.

3. Determine meaning and intent in various forms of communication, including instructive, informative, persuasive, and entertaining, as well as in everyday life.

4. Distinguish between fact and opinion, and main ideas and supporting details to draw meaning from discussions and oral presentations.

5. Listen critically, ask clarifying questions, and express an opinion; support the opinion with specific evidence from the text or another relevant source.

6. Plan and deliver oral presentations, matching purpose and message to audience, organizing content logically, and using visual aids, as appropriate.

7. Generate and display ideas, information, and images.

8. Identify strengths and weaknesses (based on established criteria) in one's own and others' presentations. 


\section{APPENDIX C}

Council for Basic Education*

English Language Arts Framework (continued)

V. Generate ideas and questions in order to develop research topics and methodologies; gather, evaluate, and synthesize data from a variety of sources; communicate discoveries in ways that suit specific purposes and audiences.

1. Develop a research topic with teacher assistance.

2. Locate relevant information from selected materials and begin to determine credibility with teacher assistance.

3. Select materials and sources to match specific research purposes and explain the importance and usefulness of the selected materials.

4. Gather information for specific purposes, with assistance, using traditional methods (e.g., library research, interviews, questionnaires) and current technology (e.g., library databases, CD-ROMs, video).

5. Organize information (e.g., take notes, outline) and target research to the specific needs of the project.

6. Give precise credit for others' ideas or information.

7. Present a report that is a culmination of the research process.

VI. Write and speak clearly and with style, using the formal conventions of the English language, including grammar, spelling, punctuation, capitalization, sentence structure, word choice, paragraphing, and figurative language.

1. Use correctly the basics of written and oral language, including grammar, sentence construction, paragraph structure, punctuation, capitalization, spelling, and usage in finished written and oral work.

2. Explain and justify decisions about use of written language rules (e.g., capitalization, punctuation) in one's own work and the work of others.

3. Distinguish between situations and context in which standard English or the use of slang is appropriate; write and speak accordingly.

4. Revise own work (based on established criteria) to improve quality and effectiveness.

VII. Read a wide range of classic and contemporary literature* from many places and periods and in many genres to build an understanding of the philosophical, ethical, and aesthetic** dimensions of significant ideas and events.

1. Identify basic figurative language and literary techniques (e.g., use of narration, dialogue, characterization) in a variety of literary works including but not limited to fiction, non-fiction, and poetry.

2. Explain how literary techniques (e.g., character, setting, plot, conflict) are used in original fiction and non-fiction to create meaning.

3. Identify the similarities and differences among selections of children's literature and the ways in which these selections reflect the cultural background of the authors and the cultures in and about which they were written.

4. Relate events, ideas, settings, and cultures of origin from one literary work to other texts and to their own lives.

5. Use previewing strategies to select texts, media, and other material based on personal interests related to particular topics, authors, or genres.

6. Review and recommend a variety of literature and media to others, articulating what is noteworthy about these selections.

7. Identify similarities and differences of ideas and presentation in various media, and relate messages to previous knowledge and experience.

From Joftus, S., \& Berman, I. (1998)

** In these standards we are defining literature as a widerange of texts, including fiction, non-fiction, biography, essay, drama, poetry, lyrics, historical novels, and expository writing.

**** aesthetic: dealing with the perception and systematic study of beauty. 


\section{APPENDIX D}

Achieve, Inc.

Criteria for Benchmarking Standards

\section{Clarity and accessibility}

- Are the standards clearly written and easy to understand?

- Are the standards specific enough to provide clear guidance to teacher, students, parents, and curriculum and test developers about what is most important for students to learn?

\section{Measurability}

- Do the standards focus on measurable content knowledge and skills?

- Is it clear from the standards how students, teacher, and parents will know that mastery of content knowledge and skills has been achieved?

\section{Comprehensiveness and focus}

- Do the standards define a comprehensive, yet manageable academic core for all students?

- Do the standards convey both the breadth and depth of knowledge and skills expected of students? Or do they emphasize one at the expense of the other?

- Are there key concepts or skills missing in the standards?

- Have choices been made about what is most important for students to learn and when?

\section{Balance}

- Do the standards define both what students should know and what they should be able to do with that knowledge? Or is one overemphasized at the expense of the other?

- Do the standards ensure that skills are learned through the study of content and not in the abstract? Or are process standards separated from content standards?

\section{Rigor}

- Are the standards as rigorous as they should be? Do the expectations described by the state standards compare favorably to those of the benchmark standards?

- When compared to the benchmark standards, when is content introduced and at which grade levels is mastery expected?

- Is there a clear progression of knowledge and skills? In other words, do the standards describe what students should know, and be able to do, with increasing depth and sophistication from grade to grade? 